\title{
Políticas públicas e segurança pública em Pernambuco: o case pernambucano e a redução da violência homicida
}

\author{
Public Policy and Public Safety in Pernambuco: the Pernambuco \\ case and homicidal violence reduction
}

\section{José Maria Pereira da Nóbrega Júnior ${ }^{1}$}

Resumo: O artigo parte de uma análise teórica das Políticas Públicas, subárea da Ciência Política, especificamente na área setorial da Segurança Pública, buscando trazer algumas de suas principais definições e conceitos dentro de um equilíbrio teórico-empírico. Para isso é analisado o case pernambucano, com base no referencial teórico do neoinstitucionalismo histórico como forma de avaliar as mudanças institucionais e o comportamento dos principais atores (os tomadores de decisão) do chamado Pacto Pela Vida (PPV) - Programa do Governo de Pernambuco para a área específica da Segurança Pública -, em seus resultados empíricos em torno da agenda formulada pelos gestores. Os principais resultados

1 Professor Adjunto II da Universidade Federal de Campina Grande (UFCG). Lotado no Centro de Desenvolvimento Sustentável do Semiárido (CDSA/UFCG). Graduado em História (2002) pela UFPE, Mestre (2005) e Doutor (2010) em Ciência Política pelo Programa de Pós-Graduação em Ciência Politica da Universidade Federal de Pernambuco (UFPE). Coordenador do Núcleo de Estudos da Violência da UFCG (NEVU). Professor no Programa de Mestrado Profissional em Administração Pública em Rede Nacional (PROFIAP). Pesquisador do NICC Núcleo de Estudos em Instituições Coercitivas e da Criminalidade da UFPE. Pesquisador do INCT- Instituto de Estudos Comparados em Administração Institucional de Conflitos (InEAC) da Universidade Federal Fluminense (UFF). Pesquisador do Núcleo de Pesquisa Instituições, Gestão Pública e Desenvolvimento Sustentável (NUGEP-CDSA/UFCG). Pesquisador do Grupo de Pesquisa Epistemologia e Método em Ciência Política Comparada (UFPE). Pesquisador do Grupo de Pesquisa Instituições da Democracia, do Estado de Direito e da Cidadania no Brasil e na América Latina (UFPB). Pesquisador do Grupo de Pesquisa Políticas Públicas em Nível Subnacional (UFCG). E-mail: jmnobrega@ufcg.edu.br

Latitude, Vol. 8, no 2, pp. 315-335, 2014

DOI: https://doi.org/10.28998/2179-5428.20140205 


\title{
Políticas públicas e segurança pública em Pernambuco: o case pernambucano e a redução da violência homicida
}

alcançados demonstram que os governos podem controlar a violência (esta medida pelos homicídios), desde que implantem políticas públicas específicas na área da segurança, equilibrando gestão com algumas mudanças no desenho institucional das instituições coercitivas (Polícias, Ministério Público e Sistema Carcerário).

Palavras-chave: Políticas Públicas, Tomadores de Decisão, Segurança Pública e Violência homicida.

\begin{abstract}
The article is based on a theoretical analysis of Public Policy, subfield of Political Science, specifically in the area of Public Security Sector, seeking to bring some of their key definitions and concepts within a theoretical and empirical equilibrium. Analyze, Pernambuco case based on the theoretical framework of historical neo-institutionalism as a way to assess the institutional changes and the behavior of the main actors (policy makers) the so-called Pacto Pela Vida (PPV) - Programme for the Government of Pernambuco the specific area of Public Safety - in their empirical results about the schedule formulated by managers. The main results show that governments can control the violence (homicides by this measure), provided that deploy specific public policies in the area of security, balancing management with some changes in the institutional design of coercive institutions (Police, Public Prosecution and Prison System) .
\end{abstract}

Keywords: Public Policy, Policy Makers, Public Safety and homicidal violence.

\section{Introdução ${ }^{2}$}

As Políticas Públicas, como área (ou subárea) da Ciência Política, são relativamente recentes como disciplina acadêmica. Nas Ciências Sociais brasileiras ainda há uma lacuna a ser preenchida para com os estudos de Políticas Públicas. Prevalecem abordagens "críticas" de teor marxista que

\footnotetext{
2 Agradeço a importante contribuição dos pareceristas da Revista Latitude. Aproveito para destacar que as possíveis falhas deste artigo são de minha inteira responsabilidade.
} 
pouco avançaram no sentido de efetivar estudos empíricos que proporcionem um produto exequível ao nível da administração pública. Até o final da década de noventa, estudos de Políticas Públicas eram majoritariamente elaborados por órgãos de governo, como o IPEA (Instituto de Pesquisa Econômica Aplicada), o IBGE (Instituto Brasileiro de Geografia e Estatística) e o DIEESE (Departamento Intersindical de Estatísticas e Estudos Socioeconômicos), só para citar alguns dos mais importantes. As universidades não conduziam trabalhos efetivos de análises de políticas públicas, salvo os seus departamentos de economia (MELO, 1999). Contudo, a Ciência Política avançou mais que as outras ciências irmãs na análise de Políticas Públicas e desde o início da década passada amadureceram em termos de estudos empíricos mais robustos (SOUZA, 2003).

Dito isto, mesmo os estudos sobre Políticas Públicas em Ciência Política tendo amadurecido, o setor de governo da Segurança Pública mostra-se incipiente do ponto de vista de formulação e análises de Políticas Públicas. Geralmente, os estudos em Políticas Públicas focam os seus esforços em avaliações de Políticas Sociais mais prementes, como Saúde, Educação, Emprego e Renda, tendo poucos estudos sobre Direitos Humanos, Gestão do Judiciário e Segurança Pública. Este último vem tomando força nos últimos cinco anos. É na tentativa de ajudar a aumentar os estudos específicos na área da Segurança, com referência teórica e empírica, que esse trabalho foi construído.

A Segurança Pública não foi vista com cuidado no processo de redemocratização brasileira, onde a instalação da poliarquia não foi suficiente para o controle da violência. Esta era vista como violência política, não se dava atenção específica ao crime comum e à violência urbana das grandes cidades como problemas específicos a serem destacados pelos gestores públicos qualificados. A ossatura institucional foi mantida inalterada conforme os ditames legais/formais do regime militar. Isso ainda é um óbice para o avanço das políticas públicas em segurança, mas há alternativas! Políticas públicas voltadas para a melhoria do desenho institucional das assim chamadas instituições coercitivas 3 , podem melhorar a situação de epidemia homicida pela qual passa a sociedade brasileira e, especificamente, a nordestina (SAPORI, 2007 e NÓBREGA JR., 2012).

${ }^{3}$ Polícias, Sistema Penitenciário, Ministério Público e Justiça. 


\section{Políticas públicas e segurança pública em Pernambuco: o case pernambucano e a redução da violência homicida}

Para ser bem sucedido em meu intento, foram construídas seções buscando equilibrar o que a literatura específica traz em sua ossatura teórica sobre Políticas Públicas com os testes das principais variáveis para o estudo das políticas públicas em segurança. A insegurança pública encontrada hoje na sociedade brasileira tem nos homicídios um dos principais, senão o principal, termômetro para a avaliação da criminalidade e da violência. Portanto, o homicídio será a proxy de violência no case específico que analiso neste paper. O caso de Pernambuco e o seu programa de Segurança Pública, o Pacto Pela Vida (PPV), será o case de políticas públicas a ser avaliado.

Destina-se a próxima seção para discutir as Políticas Públicas do ponto de vista de suas definições e conceitos, bem como tentar traçar uma ligação entre teoria e a análise empírica dos dados de violência numa outra seção. O método desenvolvido neste trabalho utiliza-se de referencial teórico para sustentar as hipóteses a serem testadas no decorrer do texto, somado a estatística descritiva e um modelo de correlação ${ }^{4}$ para medir níveis de correlação de variáveis que serão expostas no decorrer da análise específica do caso pernambucano. O Pacto Pela Vida (PPV), programa do governo de Pernambuco para a segurança, teve como meta central a redução em $-12 \%$ anuais dos homicídios neste importante estado do Nordeste. As análises dos dados, bem como o modelo de correlação utilizado buscam testar o nível das tomadas de decisão dos gestores da segurança, avaliando se tais ações desses agentes foram bem sucedidas do ponto de vista de suas metas.

Pretende-se um trabalho que não seja uma mera avaliação de políticas públicas, mas que tenha um foco no funcionamento institucional (desenho das instituições coercitivas) somada à análise do comportamento dos principais gestores da área, utilizando, para isso, o referencial teórico do neoinstitucionalismo histórico. Este consiste em avaliar o comportamento dos atores sociais em meio às instituições as quais estes estão inseridos e, ao mesmo tempo, verificar até que ponto tais instituições moldam, ou não, as suas ações e tomadas de decisão. Outro ponto da teoria é que a sua trajetória histórica importa. Ou seja, cultura e algumas simbologias

${ }^{4} \mathrm{O}$ modelo será explicado em seção específica. 
influenciam o comportamento individual do ator social, não sendo, dessa forma, uma mera análise de escolha racional do tipo econômico ${ }^{5}$.

\section{Políticas Públicas: Definições e Conceitos}

As políticas públicas como subárea da Ciência Política foca tanto nos estudos das instituições como no comportamento dos atores que nelas trabalham e nesta interação, entre agência e estrutura. Os governos em ação devem ser responsivos com os recursos públicos e devem, também, implementar políticas que sejam efetivas do ponto de vista empírico. De acordo com Diamond e Morlino (2005), a violência e a ausência de respeito à lei são elementos de desmobilização política, pois se torna muito arriscado ir às ruas. Cabe aos governos implementarem políticas públicas em segurança para reduzir este risco. De toda a forma, é importante discutir o conceito de políticas públicas em torno do debate contemporâneo na literatura especializada.

A análise de políticas públicas avança no sentido de avaliar as políticas executadas nas mais diversas áreas de governo. As Políticas Públicas como conceito são definidas por Mead (1995) como um campo dentro do estudo da política que analisa o governo à luz de grandes questões públicas (apud SOUZA, 2006, p. 24). Cabe ao governo em exercício a escolha de suas políticas públicas, quer pela continuação das políticas de governos passados ou pela elaboração de suas próprias políticas. Sua inserção na agenda do Executivo- que permeia uma série de interesses públicos e privados - se dá pelo grupo que está no poder, e, consequentemente, controla a agenda do Presidente ou do Governador (MOE, 2006).

Para Lowi (1964 e 1972) cada tipo de política pública vai encontrar formas diversas de apoio e de rejeição, onde disputas vão ocorrer em torno de sua decisão em diversas arenas no âmbito do governo/poder. Dessa forma, o papel desempenhado pelos relevantes agentes da política seria de fundamental importância para o sucesso da política pública. Daí a necessidade de se analisar as mesmas com o olhar nas instituições e no comportamento dos atores políticos que se relacionam com essas instituições. Até que ponto as instituições servem de incentivo ou de

${ }_{5}$ Para um maior aprofundamento do neoinstitucionalismo na Ciência Política contemporânea, sugiro a leitura de Hall e Taylor (2003). 


\section{Políticas públicas e segurança pública em Pernambuco: o case pernambucano e a redução da violência homicida}

restrição ao comportamento dos principais atores envolvidos é objeto do analista de políticas públicas.

Baseado na literatura, o ciclo teórico da Política Pública é de grande importância para o sucesso da mesma. Este ciclo contém seis etapas: 1) A definição da agenda (agenda setting); 2) A identificação de alternativas; 3) A avaliação das opções; 4) A seleção das opções; 5) A implementação da política pública; 6 . Julgamento ex post da mesma.

Cada etapa dessas é avaliada pelos tomadores de decisão ${ }^{6}$ e é calculada estrategicamente ao longo do período histórico analisado (STEINMO, 2008). Os governos definem suas agendas levando em consideração o reconhecimento do problema específico. Para os fins aqui instituídos, o problema é reconhecido quando há demanda política e social, sobretudo quando os eleitores/cidadãos trazem esta demanda de forma mais expressiva para os governos/governantes ${ }^{7}$.

Dessa forma, definir uma política específica para a segurança pública requer estratégias, e que estas passem pelo filtro da agenda dos tomadores de decisão; pela identificação de alternativas de políticas vis-àvis as existentes; a avaliação das opções identificadas e a partir daí, a seleção da política pública mais premente e a implementação da mesma. Por fim, tal política pública deve passar por constante avaliação e readequação, se for o caso.

Existem três indicadores que servem como termômetro para chamar a atenção dos tomadores de decisão na escolha e aplicação das políticas públicas: a) divulgação de indicadores que explanam a dimensão do problema; b) eventos, como desastres ou repetição constante do mesmo problema e c) informações, pela mídia e pela sociedade civil organizada, que mostram as falhas na política atual ou seus resultados pífios.

No Nordeste há grave descontrole dos homicídios (NÓBREGA JR, 2012). Este é um indicador importante de (in)segurança que mostra a dimensão do problema, repetindo-se numa dada série histórica e é amplamente divulgado pela mídia. Contemplando os três pontos do termômetro destacado acima.

Pernambuco, que passa por uma política específica na área da segurança pública, aparece, na região Nordeste, como o único estado a

\footnotetext{
${ }^{6} \mathrm{Na}$ literatura especializada, policy makers.

${ }^{7}$ O que O'DONNELL (1998) chama de accountability vertical.
} 
apresentar resultado de redução nos seus números de assassinatos (cf. tabela 1). Sugerindo, a princípio, que a sua política pública de segurança foi fator decisivo na redução dos homicídios.

A principal instituição coercitiva para o controle da criminalidade e da violência é a polícia. Esta, constitucionalmente, apresenta dois ciclos, onde as suas atribuições são divididas entre a Polícia Civil e a Polícia Militar. Onde a primeira investiga e procede ao inquérito administrativo policial, e a segunda realiza de modo ostensivo a segurança pública ${ }^{8}$. Há um problema de competências e de falta de cooperação entre as duas polícias, fragilizando ambas (ZAVERUCHA, 2004). Por outro lado, uma condução bem sucedida de seu desenho institucional, provocando estímulo cooperativo entre ambas as polícias, pode levar ao sucesso de seu papel institucional na redução e/ou controle da violência e do crime (KHAN e ZANETIC, 2009 e SAPORI, 2007).

No entanto, o papel da agência/tomadores de decisão das políticas públicas faz a diferença entre o sucesso e o insucesso da política de segurança. Os indicadores de homicídios no Nordeste mostram a dimensão do problema (Cf. Gráfico 1), tanto social - mudando o comportamento dos cidadãos ao tentarem se adequar a um ambiente modificado pelo crescimento da criminalidade e da violência - quanto política incapacidade das demandas da população serem respondidas pelos seus representantes eleitos pelo voto.

8 Ainda existem problemas constitucionais que dificultam as atividades das polícias brasileiras. Tais problemas esperam por solução regimental por parte do Legislativo brasileiro. 
Políticas públicas e segurança pública em Pernambuco: o case pernambucano e a redução da violência homicida

Gráfico 1. Evolução dos homicídios no Nordeste entre 2000 e 2012

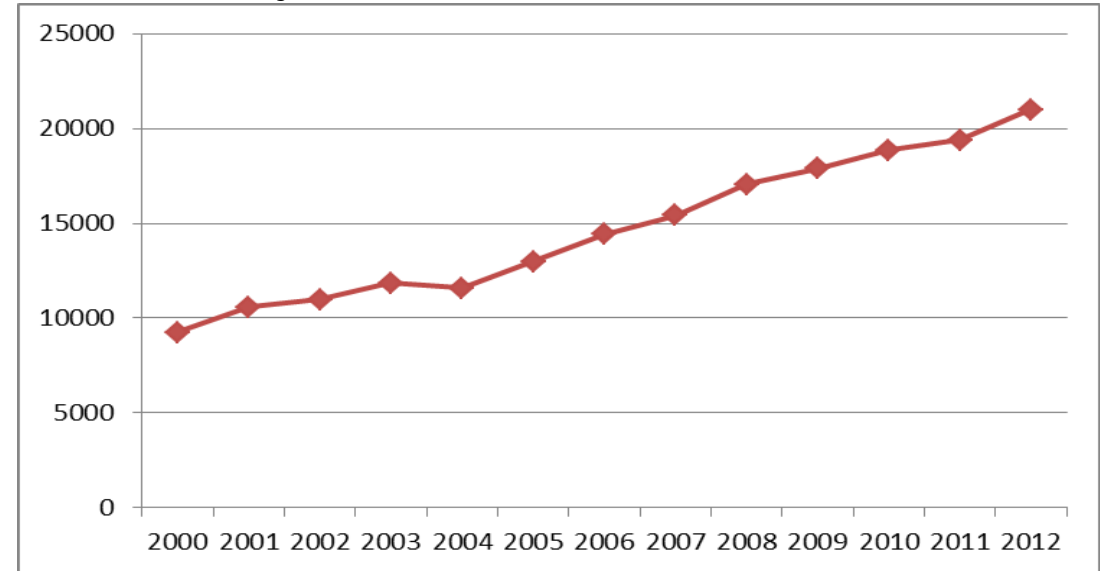

Fonte: DATASUS/MS/SV/SIM.

Ficam, deste modo, escancaradas as deficiências estruturais do sistema de justiça criminal, do qual a polícia é sua parte mais visível. O frágil papel desempenhado por tais instituições coercitivas na condução da ordem pública influencia o crescimento vertiginoso da violência, como pode ser visto adiante.

\section{A Política Pública de Segurança: O Caso de Pernambuco}

Nos últimos dez anos a Segurança Pública como serviço prestado pelo estado passou a ser destaque diante de um quadro de violência exacerbada. Antes disso, a Segurança Pública era vista como exclusivo das polícias, polícias essas que não dialogavam com os governos e que, a partir da pressão social por segurança, passaram a sofrer algumas alterações em seu comportamento provocadas por mudanças no conceito de gestão pública. Neste espaço, destaca-se o Pacto pela Vida (PPV) como o caso de política pública em segurança efetuado no Estado de Pernambuco, único estado da região Nordeste a apresentar resultado contínuo na redução de homicídios entre 2008 e 2010 (Cf. tabela 1).

\section{Análise Institucional da Política Pública de Segurança em Pernambuco}

Em algumas realidades, os tomadores de decisão da área da segurança pública apresentaram alternativas interessantes, mesmo que o desenho institucional das polícias não contribuísse para isto. São Paulo, Nova Iorque e Bogotá, por exemplo, apresentaram redução de suas taxas 
José Maria Pereira da Nóbrega Júnior

de homicídios - e de seus indicadores de violência e criminalidade de uma forma geral - em períodos relativamente curtos de tempo através de políticas públicas específicas na área da segurança (KHAN e ZANETIC, 2009; SOARES, 2008; MOCAN, 2003; NÓBREGA JR. 2010 e 2012; TORRES, 2007).

O Plano Estadual de Segurança Pública de Pernambuco, também conhecido como PACTO PELA VIDA (PPV), teve início em maio de 2007 e sua principal meta foi a redução dos homicídios em $12 \%$ ao ano. Desta forma, o PPV dialoga com o nosso método de análise que busca avaliar o peso da política pública de segurança em reduzir/controlar os homicídios ${ }^{9}$ num curto espaço de tempo, a exemplo do que aconteceu em outros países e mesmo cidades brasileiras.

Foram quatro os eixos estipulados pelo PPV com o objetivo de tanto prevenir como reduzir a violência e a criminalidade. São eles: 1) Ampliar e qualificar a defesa social; 2) Melhorar a administração prisional e promover a ressocialização; 3) Implementar a prevenção social da criminalidade; 4) Promover a articulação entre os atores do sistema de contenção criminal ${ }^{10}$.

O déficit do efetivo policial, tanto militar como civil, foi uma realidade encontrada pelo governador Eduardo Campos ${ }^{11}$. Até 2006 havia 199 policiais militares para cada grupo de cem mil habitantes e 61,7 de policiais civis em Pernambuco (NÓBREGA JR. 2011: p. 55). Sabe-se, no entanto, que as Nações Unidas recomendam que este número seja de 250 policiais por $100 \mathrm{mil}$ habitantes. Aos poucos, Campos fez novas contratações de policiais. O salto no efetivo de policiais militares foi de $25 \%$ entre 2007 e 2009, o que fez os números de policiais militares pularem de 199 policiais por cem mil habitantes para 255. Ultrapassando o limiar preconizado pela ONU.

Foram mais 1.348 policiais civis contratados, tendo um aumento de $30 \%$ no efetivo que saltou de 4.356 profissionais para 5.704. A Polícia

\footnotetext{
${ }^{9}$ Proxy de violência e crime e, por sua vez, o termômetro da (in)segurança pública. ${ }^{10} \mathrm{Na}$ dificuldade da relação civil-militar na polícia brasileira, os tomadores de decisão utilizaram o recurso da cooperação dos atores políticos envolvidos (militares e civis) tendo como estímulo reformas no desenho institucional das polícias e contrapartidas financeiras na busca dos objetivos das políticas.

${ }_{11}$ Governador de Pernambuco entre 2007 e 2014. Neste ano saiu candidato a Presidente da República, mas morreu de forma surpreendente em acidente aéreo praticamente às vésperas das eleições.
} 


\section{Políticas públicas e segurança pública em Pernambuco: o case pernambucano e a redução da violência homicida}

Militar teve um incremento de $25 \%$ no seu efetivo saltando de 17.974 policiais para 22.478, com aumento de mais de 4.500 profissionais. Novos profissionais para a polícia científica também foram contratados. Ai o aumento foi de $50 \%$ no efetivo, que saltou de 557 especialistas para 838, o que veio a reforçar o quadro de investigadores. Além dos gastos em segurança que tiveram crescimento na ordem de 195\% entre 2007 e 2009, saltando de $\mathrm{R} \$ 23$ milhões para $\mathrm{R} \$ 68$ milhões de reais ${ }^{12}$.

Mesmo com a diminuição do déficit de efetivo policial, foi na elaboração de uma política de inteligência policial, em parceria com o Judiciário e o Ministério Público ${ }^{13}$, o diferencial encontrado para a redução da criminalidade.

De toda a forma, os tomadores de decisão, a princípio, não obtiveram o resultado esperado, não obstante o investimento feito pelo governo na contratação de pessoal e na aquisição de equipamentos ${ }^{14}$. $\mathrm{O}$ PPV só começou a deslanchar no momento em que o vice-governador do Estado, João Lyra, foi substituído por Geraldo Júlio, até então Secretário de Administração e Planejamento. De forma simples e direta, o novo gestor do PPV inseriu bases do gerenciamento público em ação (baseado em análise de desempenho e cobrança de resultados). A partir de Geraldo Júlio houve a cobrança de resultados específicos de acordo com a circunscrição regional ${ }^{15}$, inteligência voltada para apreensão de homicidas contumazes, georeferenciamento de lugares críticos, melhoria técnica do banco de dados

${ }^{12}$ Dados da Secretaria de Defesa Social de Pernambuco retirados do seu Relatório "Prevenir e Reduzir a Violência e a Criminalidade" apresentado em Audiência Pública na Assembleia Legislativa de Pernambuco, em 14 de maio de 2009. Relatório entregue aos convidados em formato $p d f$ gravado em compact disc.

${ }^{13}$ Como será visto no aumento expressivo de prisões formais.

${ }^{14} \mathrm{~A}$ aquisição de novas viaturas elevou o quantitativo de transportes em Pernambuco para mais de 4.700 veículos entre motos, carros, jetskys, lanchas etc. Novos equipamentos também foram adquiridos, como colete a prova de balas (mais de sete mil coletes), pistolas ponto 40 e máquinas modernas de raio $\mathrm{X}$, só para citar alguns (Relatório "Prevenir e Reduzir a Violência e a Criminalidade" da SDS, 2009).

${ }^{15} \mathrm{O}$ Estado foi dividido por áreas estratégicas. Circunscrições nas regiões mais violentas por taxas de homicídios (CVLI-Crime Violento Letal Intencional) foram desenhadas e distribuídas para comandantes da polícia militar e delegados especiais da polícia civil. Aí também uma estratégia de cooperação entre os atores políticos policiais (civis e militares). 
criminais, relatórios periódicos sobre o andamento do PPV ${ }^{16}$. Mensalmente, realizaram-se reuniões de avaliação do Pacto contando com a participação direta do Governador do Estado. Sua presença foi um sinalizador da importância que o governo dava ao programa de segurança e que contava com o sucesso do mesmo para que o ajudasse a ser uma liderança nacional.

O êxito, em curto espaço de tempo, na redução do número de homicídios pode ser conferido na tabela a seguir.

Tabela 1. Números absolutos de homicídios - diferença no período 2008/2010 - variação \%

\begin{tabular}{|l|r|r|r|r|}
\hline & $\mathbf{2 0 0 8}$ & $\mathbf{2 0 1 0}$ & $\mathbf{0 8 / 1 0}$ & Var. $\%$ \\
\hline Região Nordeste & 16729 & 18072 & 1343 & $7,43 \%$ \\
\hline Maranhão & 1239 & 1500 & 261 & $17,40 \%$ \\
\hline Piauí & 354 & 408 & 54 & $13,24 \%$ \\
\hline Ceará & 1954 & 2509 & 555 & $22,12 \%$ \\
\hline Rio Grande do Norte & 669 & 723 & 54 & $7,47 \%$ \\
\hline Paraíba & 1027 & 1452 & 425 & $29,27 \%$ \\
\hline Pernambuco & 4345 & 3436 & -909 & $-26,46 \%$ \\
\hline Alagoas & 1878 & 2085 & 207 & $9,93 \%$ \\
\hline Sergipe & 554 & 675 & 121 & $17,93 \%$ \\
\hline Bahia & 4709 & 5284 & 575 & $10,88 \%$ \\
\hline
\end{tabular}

Fonte: Ministério da Saúde/Sistema de Informação de Mortalidade IBGE CENSO 2010/Tabela formatada pelo autor

Constata-se que Pernambuco foi o único estado da região Nordeste a apresentar redução dos homicídios (cf. tabela 1). De 2008 a 2010, período da gestão do Geraldo Júlio na pasta, o impacto percentual de variação foi de 26,4\% demonstrando que a sua administração foi positiva no que diz respeito à redução dos homicídios em Pernambuco, e que o Governador no comando da política teve papel importante.

16 Tais relatórios tem fácil acesso no site do governo http://www.pactopelavida.pe.gov.br 
Políticas públicas e segurança pública em Pernambuco: o case pernambucano e a redução da violência homicida

Gráfico 2. Taxas de Homicídios em Pernambuco 2000-2012

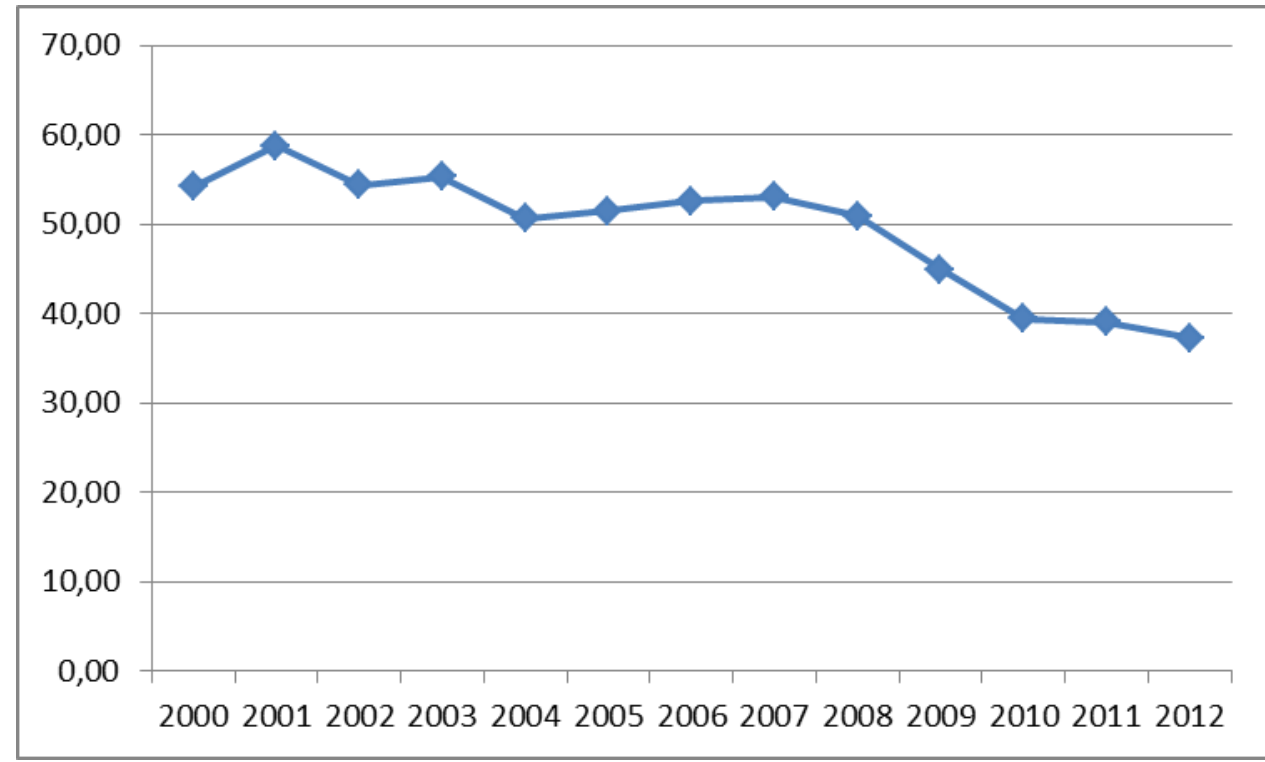

Fonte: SIM/DATASUS. Gráfico formatado e taxas calculadas pelo autor.

O período de redução se torna mais acentuado após a implementação do PPV. No início da década passada as taxas alcançaram um patamar aproximado de 60 homicídios por cada grupo de cem mil habitantes em Pernambuco - no ano de 2001 a taxa foi de 58,8/100 mil -, ou seja, a taxa do último ano da série $(2012=37,2 / 100$ mil $)$ foi inferior em mais de 30 mortes por cada grupo de cem mil habitantes em relação ao ano de 2001, com uma redução de $-36 \%$ no comparativo 2001/2012. Os anos mais expressivos de redução se deram depois da implantação do PPV em 2007 (cf. gráfico 2). Com maior impacto no período da gestão de Geraldo Júlio, pois entre 2007 e 2008, sob o comando de João Lyra, a redução foi pífia.

Novas normas de gerenciamento por busca de resultados de melhor desempenho influenciaram o trabalho da Polícia Civil, que passou a mostrar maiores eficácia e eficiência. Por exemplo, o quadro evolutivo da produção dos inquéritos policiais no Departamento de Homicídios e 
Proteção à Pessoa (DHPP) de Pernambuco apresentou substancial crescimento $^{17}$ (cf. gráfico 3).

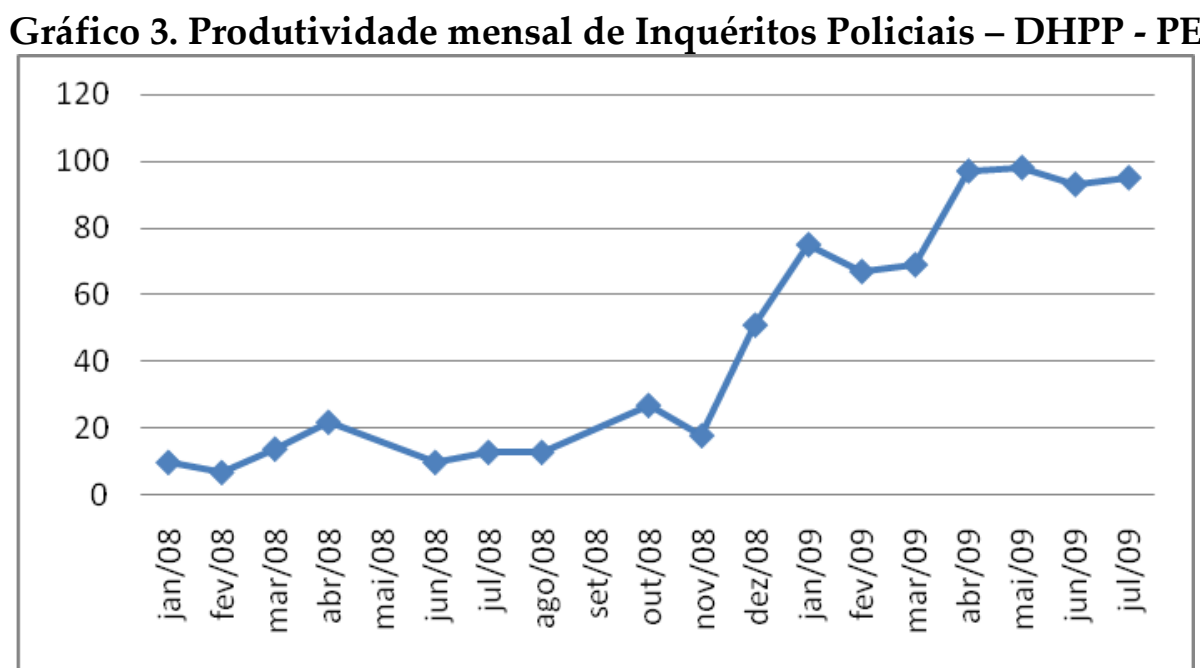

Fonte: DHPP-PE (2009)

Entre janeiro e setembro de 2008 a média mensal de inquéritos produzidos chegou perto de 15 documentos; entre outubro de 2008 e julho de 2009 a média mensal de inquéritos cresceu exponencialmente: 80,6 produzidos; entre janeiro e julho de 2009 essa média subiu para um pouco mais de 90 inquéritos. Isso demonstra como a Polícia Civil tornou-se uma instituição mais eficiente neste aspecto quantitativo. Tal ritmo, todavia, precisa ser acompanhado tanto pelo Ministério Público como especialmente pelo Judiciário de Pernambuco que tem se mostrado mais refratário às reformas gerenciais (RATTON e CIRENO, 2007). De toda a forma, como é indicado a seguir, a quantidade de prisões formais efetuadas mostra certa melhoria dessas instituições coercitivas.

Para testar o poder da variável independente 'prisões' em relação à redução dos homicídios como um dos pontos da política pública de

17 No sistema de justiça criminal a polícia é responsável pela investigação dos crimes. A promotoria é responsável pela acusação dos possíveis autores do crime. Portanto, em nada adianta uma polícia que aumenta seu calibre investigatório sem o devido acompanhamento das outras instituições do sistema de justiça como um todo (NÓBREGA JR., 2010; 2011; 2012). 


\section{Políticas públicas e segurança pública em Pernambuco: o case pernambucano e a redução da violência homicida}

segurança em Pernambuco, na próxima seção são analisadas as prisões por classificação, onde a variável independente é dividida em cinco categorias: a) prisão por homicídio qualificado; b) prisão por homicídio simples; c) prisão por latrocínio; d. prisão por CVLI; e e) prisão total (todos os tipos criminais). Numa série histórica de 2006 a 2011, também, com tal mecanismo, será avaliada a performance do Sistema de Justiça Criminal em responder as novas demandas da gestão.

\section{Prisões de Homicidas: Fator Determinante para o Controle dos Assassinatos em Pernambuco?}

Outros trabalhos já discutiram a importância dos aprisionamentos para a redução da criminalidade (KHAN e ZANETIC, 2009). Especialistas nesta área apontaram para a importância do encarceramento de "delinquentes" desde que não o fosse aleatoriamente. Ou seja, as taxas de aprisionamentos só teriam relação causal com a redução dos homicídios se fossem focadas em homicidas seriados. Com tal hipótese testada para o Estado de São Paulo, Tulio Khan e André Zanetic demonstraram que a relação entre aprisionamento de homicidas contumazes era significante como uma das variáveis importantes - para o controle dos homicídios em curto espaço de tempo (KHAN e ZANETIC, 2009).

Analisando esta hipótese para o caso do Nordeste, Nóbrega Jr. (2011) testou as relações entre o número de prisões e de homicídios, utilizando os dados do InfoPen (Banco de Dados do Sistema Penitenciário Nacional) e do SIM (Sistema de Informação sobre Mortalidade do DATASUS). Verificou-se uma baixa relação entre crescimento de prisões totais e diminuição de homicídios. Isso chamou atenção, pois na Região Nordeste tanto os indicadores socioeconômicos - que foram apontados com forte relação em algumas análises de especialistas renomados (CERQUEIRA, LOBÃO e CARVALHO, 2007) - como os níveis de aprisionamento não tiveram o mesmo impacto quando testado em relação aos homicídios. No caso de indicadores socioeconômicos clássicos, como o índice de Gini e de renda domiciliar per capita, o nível de relação foi inverso. Ou seja, os indicadores melhoraram na distribuição e no crescimento da renda, mas os níveis de violência homicida seguiram a ascendente (NÓBREGA JR. e ZAVERUCHA, 2010).

Contudo, não foi testada a relação entre homicídios perpetrados e o nível de aprisionamento de homicidas. Observando a realidade dos dados 
no Nordeste, verificou-se que os assassinatos permaneceram altos em uma dada série histórica (Cf. Gráfico 1). Salvo o Estado de Pernambuco que, principalmente nos últimos três anos da série histórica supracitada, passou a reverter seus números de assassinatos.

O próximo passo é tentar relacionar os números absolutos de homicídios e crimes violentos letais e intencionais (inserindo os latrocínios) com os níveis de aprisionamento de homicidas e latrocinas no Estado de Pernambuco. Afinal, um dos principais objetivos do PPV era aumentar o número de aprisionamentos de homicidas contumazes, o que poderia levar a uma redução dos homicídios em curto espaço de tempo.

Tabela 2. Crime Violento Letal Intencional, Prisões Totais (PRI TOT), Prisões por Homicídio Qualificado (PRI HQ), Prisões por Homicídio Simples (PRI HS), Prisões por Latrocínio (PRI LAT) e Prisões por CVLI (soma dos homicídios com Latrocínio)

\begin{tabular}{|l|l|l|l|r|r|r|}
\hline $\begin{array}{l}\text { Série } \\
\text { hist. }\end{array}$ & CVLI & $\begin{array}{l}\text { PRI } \\
\text { TOT }\end{array}$ & $\begin{array}{l}\text { PRI } \\
\text { HQ }\end{array}$ & PRI HS & $\begin{array}{l}\text { PRI } \\
\text { LAT }\end{array}$ & $\begin{array}{l}\text { PRIS } \\
\text { CVLI }\end{array}$ \\
\hline 2006 & 4470 & 15.778 & 1.071 & 407 & 672 & 2150 \\
\hline 2007 & 4556 & 18.836 & 2869 & 1709 & 600 & 5178 \\
\hline 2008 & 4345 & 19.808 & 2941 & 1956 & 647 & 5544 \\
\hline 2009 & 3901 & 21.641 & 2244 & 2845 & 514 & 5603 \\
\hline 2010 & 3443 & 23.925 & 3376 & 5688 & 540 & 9604 \\
\hline 2011 & - & 25.850 & 2265 & 3869 & 521 & 6655 \\
\hline$\%$ & $-23 \%$ & $64 \%$ & $111 \%$ & $851 \%$ & $-22 \%$ & $208 \%$ \\
\hline
\end{tabular}

Fonte: Ministério da Justiça, InfoPen (2012); SIM (2012). Tabela formatada pelo autor (2013).

As prisões por homicídios simples em Pernambuco teve incremento percentual de $1300 \%$ entre 2006 e 2010, com pequena redução em 2011. Em 2006, foram presos 407 indivíduos acusados de homicídios simples. Nos anos subsequentes as prisões cresceram expressivamente, alcançando um máximo de 5.688 presos por homicídio simples em 2010. O crescimento da variável condenação por homicídio qualificado também foi relevante, atingindo o nível de $215 \%$ entre 2006 e 2010. Já os dados de prisões por latrocínio sofreu redução de -22\% (entre 2006 e 2011), o que pode estar relacionado ao crescimento de prisões por homicídios (simples e 
Políticas públicas e segurança pública em Pernambuco: o case pernambucano e a redução da violência homicida

qualificado), pois mais prisões de homicidas podem refletir na diminuição dos latrocínios (Cf. tabela 2).

Tabela 3. Modelo de Correlação de Pearson - Variável dependente CVLI - Variáveis independentes Prisões Totais, Prisões por Homicídio Qualificado, Prisões por Homicídios Simples, Prisões por Latrocínio e Prisões de CVLI (soma de Prisões Totais, por Homicídio Qualificado, por Homicídio Simples e por Latrocínio)

\begin{tabular}{|l|l|r|r|r|r|r|}
\hline \multicolumn{2}{|l|}{ ControlVariables } & $\begin{array}{c}\text { PRI } \\
\text { TOT }\end{array}$ & PRI HQ & PRI HS & \multicolumn{1}{c|}{$\begin{array}{c}\text { PRI } \\
\text { LAT }\end{array}$} & \multicolumn{1}{c|}{$\begin{array}{c}\text { PRIS } \\
\text { CVLI }\end{array}$} \\
\hline \multirow{3}{*}{ CVLI } & Correlation &, 387 &, 652 &,- 532 &, 037 &, 047 \\
\cline { 2 - 7 } & $\begin{array}{l}\text { Significance (2- } \\
\text { tailed) }\end{array}$ &, 613 &, 348 &, 468 &, 963 &, 953 \\
\cline { 2 - 7 } & Df & 2 & 2 & 2 & 2 & 2 \\
\hline
\end{tabular}

Fonte: InfoPen I SIM. Modelo do autor.

Esses dados apresentaram razoável nível de correlação no teste destas variáveis com os homicídios em Pernambuco. O modelo de Correlação de Pearson demonstrado na tabela 3 evidencia os níveis de correlação entre os homicídios e as variáveis independentes (prisões totais, prisões de homicídio qualificado, prisões de homicídios simples, prisões de latrocínio e prisões de CVLI - que seria a soma de todos os crimes que resultaram na morte da vítima).

A correlação de Pearson é um modelo estatístico que mede a relação entre variáveis que variam entre 1 e -1 . Quanto mais próximo de zero, menor a (cor)relação. $\mathrm{O}$ sinal negativo ou positivo afirma a direção da relação entre as variáveis testadas. Os níveis de correlação das variáveis independentes prisões por homicídio qualificado (PRI HQ) e prisões por homicídio simples (PRI HS) foram as mais expressivas, com destaque para as prisões por homicídio qualificado (PRI HQ Correlation =0,652). As prisões no agregado (total) e as prisões de CVLI (que insere os latrocínios) tiveram baixa correlação, corroborando as conclusões anteriores (NÓBREGA JR., 2011 e 2012).

Respondendo à questão que intitula esta subseção pode-se afirmar que a prisão sem foco específico nos homicidas não tem resultado satisfatório no 
controle dos homicídios. Pode até não ser determinante, mas é fundamental do ponto de vista do teste de variáveis aqui exposto.

A prisão de homicidas possui, portanto, nível de correlação estatística significativo para a redução da violência homicida em curto espaço de tempo. Isto permite afirmar que esta variável teve importância estatística e influência para o sucesso do Pacto pela Vida em sua meta de reduzir os homicídios. Outra informação importante, do ponto de vista da teoria aqui utilizada, foi que a inclusão na agenda (agenda setting) de prisões de homicidas seriados e/ou contumazes se mostrou relevante na perspectiva da gestão de políticas públicas em segurança, permitindo afirmar que a tomada de decisão dos atores sociais foi importante para o resultado final.

\section{Conclusão}

Números de homicídios nos patamares vistos hoje no Brasil, em específico na Região Nordeste, são incompatíveis com regimes políticos democráticos estáveis e consolidados. Além do aspecto eleitoral explorado pelas definições procedimentalistas da democracia, é fundamental averiguar a capacidade do estado de direito em levar segurança aos cidadãos/eleitores para afirmar que uma dada democracia mostra-se consolidada.

É inadmissível eleger governos que negligenciam a área da segurança pública em suas agendas de políticas públicas. A demanda social e eleitoral por segurança já faz parte da ordem do dia há muito tempo. Pesquisas já apontam a insatisfação dos eleitores com seus governos quando o assunto é a política de segurança pública (NÓBREGA JR., 2008; IPESPE, 2008).

As políticas públicas de segurança reduzem e/ou controlaram os homicídios e a criminalidade violenta em curto espaço de tempo. Realidades conhecidas por suas altas taxas de assassinatos, como São Paulo, Bogotá, Nova Iorque e Pernambuco vêm tendo efeito redutivo neste tipo de violência em anos consecutivos. Independentemente dos contextos culturais, políticos e econômicos, quando há espaços abandonados pelo estado (e seus governos) há tendência ao crescimento da delinquência e, por sua vez, da violência (KELLING and COLES, 1996). Dessa forma, o preenchimento desses espaços só pode se dar com políticas públicas 


\section{Políticas públicas e segurança pública em Pernambuco: o case pernambucano e a redução da violência homicida}

efetivas, eficazes e eficientes, onde a participação da sociedade também se faz relevante.

A análise teórica e empírica aqui executada demonstrou como o foco nas políticas públicas de segurança pode, em curto espaço de tempo, reduzir as taxas de assassinatos. No caso de Pernambuco aponta-se que as decisões dos seus principais atores políticos na área da segurança pública e a inserção direta do Governador do Estado de Pernambuco na direção da política foi fundamental para a redução dos homicídios. A Correlação de Pearson indicou que a prisão de indivíduos acusados por homicídios qualificado e simples teve a maior correlação na redução dos assassinatos (CVLI), mostrando que, a inclusão dessa variável independente na política pública de segurança foi uma ação responsiva acertada do gestor. Dessa forma, a política pública de segurança acertou ao investir na qualificação tanto da polícia judiciária (elaboração de inquéritos mais qualificados) como no trabalho de inteligência policial (maior número de prisões executadas) fomentando a parceria entre as instituições que fazem parte do Sistema de Justiça Criminal.

\section{Bibliografia}

CERQUEIRA, Daniel; LOBÃO, Waldir; CARVALHO, Alexandre (2007). “O jogo dos sete mitos e a miséria da segurança pública no Brasil". Homicídios no Brasil. Org. Marcus Vinicius Gonçalves da Cruz e Eduardo Batittuci. Ed. FGV. Rio de Janeiro.

DIAMOND, Larry e MOLINO, Leonardo (eds.) (2005).Assessing the Quality of Democracy.Baltimore. Johns Hopkins University Press.

GERRING, John (2007). "ReviewArticle: The Mechanismic Worldview: Thinking Inside the Box". British Journal of Political Science. 38. 161-179.

HALL, Peter e TAYLOR, Rosemary (2003), “As três versões do neoinstitucionalismo". Lua Nova. No. 58. 
IPESPE (2008). Pesquisa realizada pelo Instituto de Pesquisa Econômica e Social de Pernambuco. Barômetro Pernambuco (Recife), $7^{\text {a }}$ Rodada, 30-31 de agosto.

KELLING, George and COLES, Catherine (1996), Fixing Broken Windows: Restoring Order and Reducing Crimes in Our Communities. New York Free Press.

KHAN, Túlio e ZANETIC, André (2009). “O papel dos municípios na segurança pública". Coleção Segurança com Cidadania. Ano 1. № 1. Subsídios para Construção de um Novo Fazer Segurança Pública.

LOWI, Theodor (1964). "American Business, Public Policy, Case Studies and Political Theory". World Politics.16. Pp. 677-715.

LOWI, Theodor (1972). "Four Systems of Policy, Politics and Choice”.Public Administration Review. 32. Pp. 298-310.

MEAD, L. M. (1995). “Public Policy: vision, potential, limits". Policy Currents.Pp. 1-4.

MELO, Marcus André (1999), "Estado, governo e políticas públicas", in Sergio Miceli (org.), O que ler na ciência social brasileira (1970-1995), São Paulo, Sumaré

MOCAN, Nanci (2003), "Crime Control: Lessons from the New York City Experience". Paper to be given at the International Seminar on Crime and Violence Prevention in Urban Settings, Bogotá, Colômbia.

MOE, Terry (2006). "Power and Political Institutions" in Ian Shapiro, Stephen Skowronek e Daniel Galvin (orgs.).RethinkingPoliticalInstitutions. New York: New York University Press.

NÓBREGA JR, José Maria (2010), “A dinâmica dos homicídios no Nordeste e em Pernambuco". DILEMAS: Revista de Estudos de Conflito e Controle Social - Vol. 3 - no 10 - OUT/NOV/DEZ - pp. 51-74. 


\section{Políticas públicas e segurança pública em Pernambuco: o case pernambucano e a redução da violência homicida}

NÓBREGA JR, José Maria; ZAVERUCHA, Jorge e ROCHA, Enivaldo C. (2009). "Homicídios no Brasil: revisando a bibliografia nacional e seus resultados empíricos." Revista Brasileira de Informação Bibliográfica em Ciências Sociais - BIB. N. 67. Pp. 75-94.

NÓBREGA JR. José Maria; ZAVERUCHA, Jorge e ROCHA, Enivaldo (2011). "Mortes Por Agressão Em Pernambuco E No Brasil: Um Óbice Para A Consolidação Da Democracia." Revista de Sociologia e Política, Curitiba, v. 19 , n. 40 , p. 103-114.

NÓBREGA JR., José Maria (2008). “Barômetro da Violência e da Segurança na Cidade do Recife”. Política Hoje. Vol. 17. № 1.

NÓBREGA JR., José Maria (2009). Semidemocracia brasileira: as instituições coercitivas e práticas sociais. Nossa Livraria Editora. Recife.

NÓBREGA JR., José Maria (2011). "Os Homicídios no Nordeste Brasileiro". O Panorama dos Homicídios no Brasil. Segurança, Justiça e Cidadania. Secretaria Nacional de Segurança Pública. Ministério da Justiça. Ano 3. № 6.

NÓBREGA JR., José Maria (2012). Homicídios no Nordeste. Dinâmica, relações causais e desmistificação da violência homicida. Ed. UFCG. Campina Grande. Paraíba.

NÓBREGA JR., José Maria e ZAVERUCHA (2010). “Violência homicida no Nordeste brasileiro: uma refutação às explicações baseadas na desigualdade e na pobreza". Dossiê Segurança Pública.Anuário Antropológico. Departamento de Antropologia da UnB. Tempo Brasileiro. Vol. 2 (2009). Pp. 53-87.

O'DONNELL, Guillermo (1998), “Accountability Horizontal e novas poliarquias". Lua Nova. № 44.

RATTON, José L. e CIRENO, Flávio (2007). Violência Endêmica. Relatório de Pesquisa. Homicídios na Cidade do Recife: Dinâmica e Fluxo no Sistema 
José Maria Pereira da Nóbrega Júnior

de Justiça Criminal. Revista Do Ministério Público Do Estado De Pernambuco, Recife.

SAPORI, L. F. (2007), Segurança Pública no Brasil: desafios e perspectivas. FGV Editora. Rio de Janeiro.

STEINMO, Sven (2008). "Historical Institutionalism" in Donatella Della Porta and Michael Keating (orgs.) Approaches and Methodologies in the Social Sciences. Cambridge. Cambridge University Press. 118-138.

SOARES, Gláucio A. D. (2008). Não Matarás. Desenvolvimento, desigualdade e homicídios. FGV Editora. Rio de Janeiro.

SOUZA, Celina (2003). "Estado Do Campo" Da Pesquisa Em Políticas Públicas No Brasil" RBCS Vol. 18 nº. 51 fevereiro/2003

SOUZA, Celina (2006). "Políticas Públicas: uma revisão da literatura". Sociologias. Ano 8. № 16. Pp. 20-45.

TORRES, Fabio S. (2007), Las Cuentas de La Violencia, Economía Universidad de los Andes, Bogotá, Grupo Editorial Norma.

ZAVERUCHA, Jorge (2004). Polícia Civil de Pernambuco: o desafio da reforma. Ed. UFPE. Recife, PE.

Enviado:

$10 / 07 / 2014$

Aprovado:

21.10.2014 